\title{
Physiological and Psychological Effects of Scent of Soil on Human Beings
}

\author{
Tateyuki Morisawa1 ${ }^{*}$, Kazuyo Hanyu², Hidetoshi Mori ${ }^{3}$, Kenji Tamura ${ }^{2}$ \\ ${ }^{1}$ Biosphere Resource Science and Technology Graduate School of Life and Environmental Science, University of Tsukuba, \\ Tsukuba, Japan \\ ${ }^{2}$ Faculty of Life and Environmental Sciences, University of Tsukuba, Tsukuba, Japan \\ ${ }^{3}$ Division of Health Sciences, Graduate School of Technology and Science, Tsukuba University of Technology, Tsukuba, Japan \\ Email: *s1530279@s.tsukuba.ac.jp
}

How to cite this paper: Morisawa, T., Hanyu, K., Mori, H. and Tamura, K. (2017) Physiological and Psychological Effects of Scent of Soil on Human Beings. Open Journal of Soil Science, 7, 235-244.

https://doi.org/10.4236/ojss.2017.79017

Received: August 11, 2017

Accepted: September 11, 2017

Published: September 14, 2017

Copyright $\odot 2017$ by authors and Scientific Research Publishing Inc. This work is licensed under the Creative Commons Attribution International License (CC BY 4.0).

http://creativecommons.org/licenses/by/4.0/

\begin{abstract}
This study examines heart rate and heart rate fluctuation when subjects are presented with the scent of soil and their psychological changes as expressed by scores of the Profile of Mood States (POMS) and Visual Analog Scale (VAS) as indexes. In the experiment, we directed the subjects to rest in a sitting position for $5 \mathrm{~min}$. (Pre.), to smell the scent for $1 \mathrm{~min}$. (No Stim., Stim.), and to rest in a sitting position for $15 \mathrm{~min}$. (Post 5, Post 10, Post 15). Psychological evaluation was performed before and after the experiment (Pre., Post). The scent stimulation was made by opening/closing a bottle with screw-on cap that contained the soil. In the control group, the bottle is always closed. In the stimulus group, the bottle was opened only at the time of Stim. For the physiological evaluation, although we could observe no change in the control group, in the stimulation group, the subjects' heart rates decreased at Stim. and Post 15. For the psychological evaluation, VAS scores of "Feel relaxed" and "Feel soothed" increased and POMS scores of "Strain-Uneasiness", "Anger-Hostility", and "Confusion" decreased. In open-ended questions, some of the subjects recalled memories of insect-collecting, horticulture, forests and parks. There was a negative correlation between heart rate decrease (Stim.) and increase in the VAS scores of "Feel relaxed" $(r=-0.896, p<0.001)$ and "Feel soothed" $(r=-0.684, p=0.014)$. The healing effects from the scent of soil included subjects' memories that were considered to have influenced the heart rate.
\end{abstract}

\section{Keywords}

Soil, Heart Rate Variability, POMS, VAS, Autobiographical Memory 


\section{Introduction}

Forests constitute $30 \%$ of the total land area on earth. Forests occupy $68 \%$ or $2 / 3$ of the total land area in Japan, making it the country with the second highest percentage of forests in the world, after Finland. The healing effect of forests has attracted wide attention in recent years and can be considered one of the benefits of forest resources. There have been studies that reported a reduction in stress [1] [2] and a decline in the mortality rate from cardiac disease by "forest bathing" [3]. In the forest, fallen leaves and withered branches cover the forest floor. The layer of such deposited fallen leaves is called the humus layer. In soil science, it is called the $\mathrm{O}$ layer (in forestry Ao layer). Organic matter in the $\mathrm{O}$ layer decomposes within several years. Some of this matter is emitted into the atmosphere as carbon dioxide or becomes dissolved organic matter and remains in the soil as microbial metabolites. Thus, in the forest, fallen leaves go into the soil, which results in material circulation [4]. Soil is not only the largest feature of the forest, but also is a source of its scent. However, there has been very little attention paid to the effects of the scent that is emitted from the soil. Interest is increasing in clarifying the effect of the scent of a forest on humans in the field of aromatherapy. In it, the report of an antitumor action [5] [6] [7] etc. is made about the effect to the humans of monoterpenes, such as an herb and a needle-leaf tree. Nakamura, et al. examined and identified the components of the forest atmosphere such as terpenes, and reported that human beings can easily absorb such components [8]. However, there are no reports on the scent that occurs from soil, which is one of the biggest features of the forest environment. Hanyu et al. [9] examined soil and reported that the scent and texture of soil in a forest have a relaxing effect; however, there are very few reports on the effect of the scent of soil on human beings. Accordingly, this report aims to examine the effect of the scent of forest soil on human beings.

\section{Methods}

\subsection{Subjects}

Twelve male students (age: $24.6 \pm 1.8$ years old) with no olfactory disturbance received an explanation of the purpose of this study and gave their written consent to participate in accordance with the principles of the Helsinki Accords. The subjects selected one of 12 cards. Of the 12 cards, six cards were labeled "1st control group/2nd stimulation group" and the other six cards were labeled "1st stimulation group/2nd control group. The experiment was conducted from 23 November to 5 December in 2015.

\subsection{Test Samples}

The soil samples that were used for scent stimulation were collected from the green belt area at the University of Tsukuba administrative building north parking lot $\left(36^{\circ} 647.40^{\prime} \mathrm{N} 140^{\circ} 6^{\prime} 14.10^{\prime \prime} \mathrm{E}\right)$. The vegetation in the artificial forest from which the soil was collected included mainly evergreen oak trees, dotted Japa- 
nese oak, Japanese cedar, maple, and chestnut trees. The soil samples (taken from the organic sedimentary layer containing fallen leaves of evergreen oak trees to a depth of about $15 \mathrm{~cm}$ including topsoil) were put into a bottle measuring $15 \mathrm{~cm}$ in height and $10 \mathrm{~cm}$ in diameter with a screw-on cap.

\subsection{Sample Analysis}

Qualitative analysis of the soil for scent stimulation was conducted using GC/MS (GCMS-QP2010 Plus, Shimadzu Corp.) by the headspace method. The collected soil was put into a vial with $10 \mathrm{cc}$ septum and $2 \mathrm{ml}$ was poured from the headspace by a split trace after leaving it standing at $23^{\circ} \mathrm{C}$ for 1 hour. The column (Stabilwax ${ }^{\oplus}$-DA, Shimadzu Corp.) used was $0.25 \mathrm{~mm}$ i.d. $\times 30 \mathrm{~m}$ with film thickness of $0.25 \mu \mathrm{m}$. Ion source temperature and interface temperature were set at $200^{\circ} \mathrm{C}$; in the oven program, the temperature was first set at $40^{\circ} \mathrm{C}$ for $5 \mathrm{~min}$. and then increased to $200^{\circ} \mathrm{C}$ at increments of $5^{\circ} \mathrm{C} / \mathrm{min}$. and when it reached $200^{\circ} \mathrm{C}$, was then set for $10 \mathrm{~min}$. at this temperature. Each component that was identified by a similar search (GCMS solution, Shimadzu Corp.) was expressed by the area percentage method (Table 1).

\subsection{Method of Evaluation}

Physiological evaluation was performed by measuring heart rate and heart rate fluctuation for which 2-lead electrocardiogram recorders were used. The R-R interval was computed with a memory heart rate meter (LRR-03, GMS), and heart rate (HR), low frequency component (LF; $0.04-0.15 \mathrm{~Hz}$ ), High frequency component (HF; $0.15-0.4 \mathrm{~Hz}$ ), and ratio (LF/HF) of LF component and HF component were analyzed by the heart rate fluctuation real-time analysis program (MemCalc/Tarawa, GMS) [10]. Psychological evaluation was made using the Visual Analogue Scale (VAS), Profile of Mood States (POMS), and open-ended questions. Measurement of VAS was conducted using a measure where the left end $(0 \mathrm{~mm})$ of the scale $(100 \mathrm{~mm})$ indicated a state of "no feeling" and the right end $(100 \mathrm{~mm})$ indicated a state where the subject had "maximum feeling". The subjects were directed to indicate their current state by checking the scale and evaluating the VAS results by the distance $(\mathrm{mm})$ from the left end of the scale to the checked point $(\mathrm{mm})$. Using the VAS scale, there were 12 questions for the control group and 13 for the stimulation group with the addition of a question for evaluating the scent of soil (Table 2). The short form of the Profile of Mood States (POMS-SF) was used to evaluate 30 items on mood states with a

Table 1. Terpenes from the soil for scent stimulation.

\begin{tabular}{cc}
\hline Component & Composition ratio (\%) \\
\hline$\alpha$-Pinene & 14.96 \\
3-Carene & 39.81 \\
$\beta$-Myrcene & 21.27 \\
D-Limonene & 23.97 \\
\hline
\end{tabular}


five-grade evaluation and to determine T-Scores for the six mood scales of "Tension-Anxiety", "Depression", "Anger-Hostility", "Vigor", "Fatigue” and "Confusion".

\subsection{Measurement Procedures}

The experiment was conducted in a room with a room temperature of $24^{\circ} \mathrm{C} \pm$ $0.5^{\circ} \mathrm{C}$, and relative humidity of $31 \% \pm 1 \%$. The subjects sat quietly for about 10 min. after entering the room. Physiological evaluation was measured as follows: 5 min. rest (Pre.), 1 min. no stimulation or stimulation (No Stim. or Stim.), and $15 \mathrm{~min}$. rest. The subjects sat with their eyes closed during measurement (Pre. to Post 15). Psychological evaluation (VAS and POMS) was conducted before and after (Pre., Post) physiological evaluation. At Post, the evaluation included the time when the scent was detected.

\subsection{Method of Stimulation}

Before starting the experiment, the bottle with a screw-on cap for scent stimulation into which soil was put, was positioned so that the opening of the bottle was $10 \mathrm{~cm}$ from the nose of the subject. The scent stimulation was made by opening/closing the cap. After $5 \mathrm{~min}$. rest with the cap closed (Pre.) the control group sat with the cap closed (No Stim.) and the stimulation group (Stim.) sat with the cap open so they were able to smell the scent. After that, both groups rested for 15 min. (Post 5, Post 10, Post 15) with the cap closed.

\subsection{Method of Evaluation}

For physiological evaluation, the mean for each value of Pre., No Stim., Stim., Post 5, Post 10, and Post 15 was determined. For heart rate (HR) and heart rate fluctuation (LF, HF, LF/HF) the Fisher (LSD) multiple comparison was conducted on each group in the generalized linear model for five points (Pre., Stim., Post 5, Post 10, Post 15). Temporal changes between both groups were examined by two-way analysis of variance (interaction) in the generalized linear model. Wilcoxon signed-rank test was used for VAS and POMS. The data for the physiological/psychological evaluation was indicated by mean \pm standard deviation.

\section{Result}

\subsection{Physiological Evaluation}

Table 3 indicates changes in heart rate (HR) and heart rate fluctuation (LF, HF,

Table 2. Questions for VAS.

\begin{tabular}{cclc}
\hline Feel tired & Feel discomfort & Feel disgust & Feel depressed \\
\hline Feel nervous & Feel excited & Feel thrilled & Feel refreshed \\
Feel comfortable & Feel relaxed & Feel soothed & Feel sleepy \\
Like scent of soil & & & \\
\hline
\end{tabular}


LF/HF). Heart rate significantly decreased after soil scent stimulation as indicated by the following results: Pre. level was $74.3 \pm 6.5 \mathrm{bpm}$; during Stim. ( $\mathrm{p}=$ 0.01 ), it was $72.0 \pm 6.8 \mathrm{bpm}$ and the level at Post 15 (p=0.022) was $71.6 \pm 7.8$ $\mathrm{bpm}$. There was also no interaction. Both control and stimulation groups showed no change in LF, HF, and LF/HF ratio and expressed no interaction.

\subsection{Psychological Evaluation}

\subsubsection{POMS}

Table 4 indicates T-Scores of POMS before and after the experiment. In the control group, "Tension-Anxiety" significantly decreased from a Pre. level of $41.5 \pm 8.6$ to a Post level ( $\mathrm{p}=0.017$ ) of $38.9 \pm 7.2$ "Vigor" also showed a significant decrease from a Pre. level of $37.7 \pm 7.2$ to a Post level $(\mathrm{p}=0.026)$ of $34.8 \pm$ 5.2. In the stimulation group, significant decrease was seen for "Tension-Anxiety" which decreased from a Pre. level of $45.4 \pm 14.7$ to a Post level ( $\mathrm{p}=0.017$ ) of 38.1 \pm 7.0 and "Anger-Hostility" decreased from a Pre. level of $41.5 \pm 4.2$ to a Post level ( $\mathrm{p}=0.011$ ) of $38.2 \pm 1.8$ and "Confusion" decreased from a Pre. level of $54.3 \pm 13.9$ to a Post level $(\mathrm{p}=0.018)$ of $47.6 \pm 8.6$.

\subsubsection{VAS}

Table 5 shows VAS scores before and after the experiment. In the control group "Feel excited" significantly decreased from the Pre. level of $26.0 \pm 20.8 \mathrm{~mm}$ to a Post level ( $\mathrm{p}=0.009$ ) of $19.7 \pm 21.4 \mathrm{~mm}$ and "Feel thrilled" decreased from a Pre. level of $26.2 \pm 20.6 \mathrm{~mm}$ to a Post level ( $\mathrm{p}=0.033$ ) of $19.5 \pm 20.7 \mathrm{~mm}$. In the stimulation group, "Feel nervous" decreased significantly from a Pre. level of

Table 3. Changes in heart rate and heart rate fluctuation.

\begin{tabular}{cccccc}
\hline & Pre & (No) Stim. & Post 5 & Post 10 & Post 15 \\
\hline Control Group & & & & & \\
HR (bpm) & $72.0 \pm 10.2$ & $72.7 \pm 6.2$ & $73.9 \pm 8.3$ & $73.8 \pm 8.3$ & $72.8 \pm 7.6$ \\
LF (msec $\left.{ }^{2}\right)$ & $836.5 \pm 126.6$ & $737.3 \pm 136.7$ & $1054.1 \pm 273.5$ & $920.7 \pm 194.3$ & $974.0 \pm 150.3$ \\
HF (msec $\left.{ }^{2}\right)$ & $410.1 \pm 91.5$ & $386.8 \pm 74.3$ & $351.2 \pm 72.1$ & $325.1 \pm 75.7$ & $398.4 \pm 88.7$ \\
LF/HF ratio & $3.8 \pm 1.0$ & $5.3 \pm 3.0$ & $10.6 \pm 6.7$ & $8.2 \pm 3.9$ & $5.5 \pm 2.3$ \\
Stimulation & & & & & \\
Group & & & & & \\
HR (bpm) & $74.3 \pm 6.5$ & $72.0 \pm 6.8 *$ & $74.2 \pm 7.1$ & $73.0 \pm 6.3$ & $71.6 \pm 7.8^{*}$ \\
LF (msec $\left.{ }^{2}\right)$ & $908.6 \pm 157.8$ & $1296.7 \pm 325.4$ & $855.8 \pm 118.2$ & $975.4 \pm 130.6$ & $1081.9 \pm 236.2$ \\
HF (msec $\left.{ }^{2}\right)$ & $374.9 \pm 134.5$ & $616.2 \pm 263.3$ & $368.2 \pm 123.0$ & $399.5 \pm 90.5$ & $457.5 \pm 113.9$ \\
LF/HF ratio & $8.4 \pm 3.7$ & $9.8 \pm 6.3$ & $9.1 \pm 3.7$ & $7.4 \pm 4.0$ & $6.1 \pm 3.1$ \\
\hline
\end{tabular}

${ }^{*} \mathrm{p}<0.05$; The values are mean $\pm \mathrm{SD}$; The control group first rested for $5 \mathrm{~min}$. (Pre.), next, they smelled no scent for $1 \mathrm{~min}$. (No stim.), and then they rested again for 0 to $5 \mathrm{~min}$. (Post 5), for 5 to $10 \mathrm{~min}$. (Post 10), and for 10 to $15 \mathrm{~min}$. (Post 15). The stimulation group first rested for $5 \mathrm{~min}$. (Pre.), next, they were presented with the scent of soil for $1 \mathrm{~min}$. (Stim.), and then rested for 0 to $5 \mathrm{~min}$. (Post 5), for 5 to $10 \mathrm{~min}$. (Post 10), and for 10 to $15 \mathrm{~min}$. (Post 15). 
Table 4. Changes in POMS scores before and after the experiment (T-scores).

\begin{tabular}{ccccc}
\hline & \multicolumn{2}{c}{ Control group } & \multicolumn{2}{c}{ Stimulation group } \\
\cline { 2 - 5 } & Pre. & Post & Pre. & Post \\
\hline Tension-Anxiety & $41.5 \pm 8.6$ & $38.9 \pm 7.2^{*}$ & $45.4 \pm 14.7$ & $38.1 \pm 7.0^{*}$ \\
Depression & $43.1 \pm 5.0$ & $42.5 \pm 4.2$ & $47.7 \pm 12.2$ & $42.3 \pm 3.3$ \\
Anger-Hostility & $38.7 \pm 2.5$ & $38.2 \pm 2.4$ & $41.5 \pm 4.2$ & $38.2 \pm 1.8^{*}$ \\
Vigor & $37.7 \pm 7.2$ & $34.8 \pm 5.2^{*}$ & $37.2 \pm 6.5$ & $37.6 \pm 6.1$ \\
Fatigue & $44.1 \pm 9.5$ & $45.1 \pm 9.8$ & $48.2 \pm 10.6$ & $43.5 \pm 11.2$ \\
Confusion & $49.6 \pm 9.9$ & $48.2 \pm 5.9$ & $54.3 \pm 13.9$ & $47.6 \pm 8.6^{*}$ \\
\hline
\end{tabular}

POMS: Profile of Mood States; ${ }^{\star} \mathrm{p}<0.05$; The values are mean \pm SD.

Table 5. Changes in VAS scores before and after the experiment and evaluation of the scent of soil.

\begin{tabular}{ccccc}
\hline & \multicolumn{2}{c}{ Control group } & \multicolumn{2}{c}{ Stimulation group } \\
\cline { 2 - 5 } & Pre. & Post & Pre. & Post \\
\hline Feel tired & $23.6 \pm 16.9$ & $31.6 \pm 19.8$ & $43.0 \pm 25.5$ & $33.1 \pm 16.2$ \\
Feel discomfort & $18.1 \pm 15.2$ & $17.5 \pm 14.4$ & $28.1 \pm 25.3$ & $28.9 \pm 27.7$ \\
Feel disgust & $8.7 \pm 9.4$ & $18.0 \pm 16.2$ & $18.3 \pm 14.7$ & $20.2 \pm 19.7$ \\
Feel depressed & $9.9 \pm 10.8$ & $8.2 \pm 7.7$ & $19.5 \pm 21.7$ & $15.6 \pm 17.5$ \\
Feel nervous & $19.7 \pm 18.7$ & $12.1 \pm 10.1$ & $38.3 \pm 25.9$ & $13.0 \pm 14.1^{*}$ \\
Feel excited & $26.0 \pm 20.8$ & $19.7 \pm 21.4^{*}$ & $25.8 \pm 20.6$ & $22.4 \pm 22.7$ \\
Feel thrilled & $26.2 \pm 20.6$ & $19.5 \pm 20.7^{*}$ & $31.3 \pm 18.1$ & $31.7 \pm 22.8$ \\
Feel refreshed & $31.8 \pm 0.2$ & $20.3 \pm 19.5$ & $33.4 \pm 21.7$ & $32.8 \pm 19.4$ \\
Feel comfortable & $29.8 \pm 19.1$ & $26.8 \pm 8.5$ & $33.5 \pm 21.8$ & $44.8 \pm 21.8^{*}$ \\
Feel relaxed & $33.1 \pm 17.6$ & $28.1 \pm 22.1$ & $36.9 \pm 23.3$ & $52.7 \pm 16.1^{*}$ \\
Feel soothed & $22.8 \pm 20.3$ & $22.0 \pm 19.7$ & $25.8 \pm 23.3$ & $46.2 \pm 20.5^{*}$ \\
Feel sleepy & $24.5 \pm 18.3$ & $31.8 \pm 15.9$ & $32.5 \pm 15.2$ & $42.5 \pm 22.5$ \\
Like scent of soil & & & & $54.6 \pm 6.0$ \\
\hline
\end{tabular}

VAS: Visual Analogue Scale; ${ }^{*} \mathrm{p}<0.05$; The values are mean \pm SD.

$38.3 \pm 25.9 \mathrm{~mm}$ to a Post level $(\mathrm{p}=0.012)$ of $13.0 \pm 14.1 \mathrm{~mm}$, and "Feel comfortable" significantly increased from a Pre. level of $33.5 \pm 21.8 \mathrm{~mm}$ to a Post level ( $\mathrm{p}=0.050)$ of $44.8 \pm 21.8 \mathrm{~mm}$. "Feel relaxed" increased from a Pre. level of $36.9 \pm 23.3 \mathrm{~mm})$ to a Post-level $(\mathrm{p}=0.041)$ of $52.7 \pm 16.1 \mathrm{~mm}$, "Feel soothed" increased from a Pre. level of $25.8 \pm 23.3 \mathrm{~mm}$ to a Post level ( $\mathrm{p}=0.038)$ of $46.2 \pm$ $20.5 \mathrm{~mm}$.

\subsection{Image of Soil Scent}

We asked the stimulation group open-ended questions about their image of soil scent after they had smelled the soil. All the subjects gave a reply except for one. 
Eight subjects imagined landscapes and experiences related to soil scent, and one subject had no image. Two participants replied as to whether they liked the soil scent or not (Table 6).

\section{Discussion and Conclusion}

In this study, we compared subjects which were presented with the scent of soil (stimulation group) and those which were not (control group). Consequently, although the control group showed no physiological changes, the stimulation group showed a significant decrease in heart rate (Stim., Post 15). The heart rate is determined by the firing frequency of the sinus node (pacemaker cells). This frequency is influenced by the dominant sympathetic nerve and vagus nerve, thus leading to either excitability or inhibitory. For this reason, periodic activity of the brain stem and higher order cerebral cortex that synchronize with signals from arteries and veins and changes in blood pressure influence behavior, emotions, circadian rhythm, which increase through hyperactivity of sympathetic nerve functions, and decrease through hyperactivity of parasympathetic nerve functions [11]. In this study, the heart rate of the stimulation group decreased, but there was no significant difference between HF that is a parasympathetic nerve index of heart rate fluctuation and LF/HF that is a sympathetic nerve index. Thus, we conclude that neither the parasympathetic nerves nor the sympathetic nerves function independently. In the open-ended questions about what kind of image subjects associated with the soil scent, some of the answers included "insect collecting" in the mountains, a forest, and horticultural therapy. A study on POMS reported that "forest bathing" improved mental health [12] and horticultural therapy reduced negative emotions [13]. For psychological evaluation, POMS scores of "Tension-Anxiety" and "Vigor" decreased in the control group. Moreover, VAS scores of "Feel excited" and "Feel thrilled" decreased. In the stimulation group, POMS scores of "Tension-Anxiety", "Anger-Hostility"

Table 6. Image of the scent of soil.

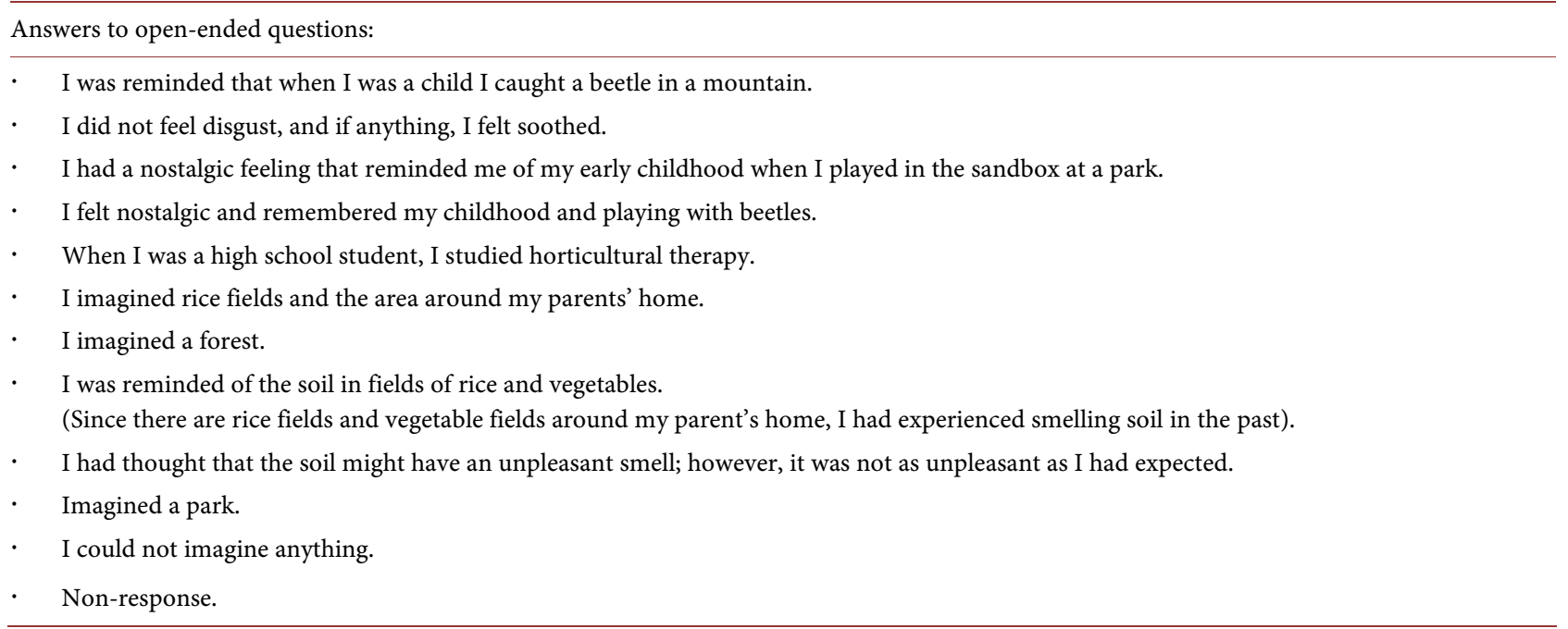


and "Confusion" decreased. In addition, VAS scores of "Feel nervous" decreased and "Feel comfortable", "Feel relaxed" and "Feel soothed" increased. From the above results, we conclude that subjects expressed improvement in their mood and were more relaxed when they were presented with the scent of soil. Some of the answers indicated that the scent of soil recalled childhood memories with subjects using such phrases as "in my early childhood", "in my childhood" or "when I was a child". In many cases, the scent made subjects recall memories of early childhood that were older than those created by visual or verbal cues [14] and raised a more emotional response [15]. The sense of smell enters the limbic system which is responsible for processing memory and creating emotion and reaches the hypothalamus that is also an autonomic nerve center. Accordingly, the emotional response from an individual who is stimulated by a scent can cause physiological changes in brain waves and various autonomic nerve functions. The heart rate is adjusted by the autonomic nervous system or endocrine system, and can change according to the subject's posture, and physical and mental activities [16]. Therefore, for the heart rate that showed significant difference, we performed a Pearson's correlation analysis among the degrees of changes at the points of Stim and Post 15 against Pre, and the degree of changes at the point of Post against Pre in VAS and POMS, and examined the psychological factors related to heart rate (Table 7). As a result, the degree to which the heart rate decreased after smelling soil scent had a significant negative correlation

Table 7. Correlation between the changes in heart rate in the stimulation group and the degree of VAS and POMS.

\begin{tabular}{ccc}
\hline & HR (Stim.-Pre.) & HR (Post 15-Pre.) \\
\hline VAS (Post-Pre.) & 0.013 & -0.091 \\
Feel tired & -0.035 & -0.326 \\
Feel discomfort & 0.164 & -0.212 \\
Feel disgust & -0.120 & -0.558 \\
Feel depressed & 0.049 & -0.489 \\
Feel nervous & -0.127 & -0.571 \\
Feel excited & $0.588^{*}$ & 0.069 \\
Feel thrilled & -0.347 & 0.145 \\
Feel refreshed & -0.511 & 0.077 \\
Feel comfortable & $-0.896^{* * *}$ & 0.034 \\
Feel relaxed & $-0.684^{*}$ & 0.166 \\
Feel soothed & 0.169 & 0.320 \\
Feel sleepy & & -0.277 \\
POMS (Post-Pre.) & -0.138 & 0.126 \\
Tension-Anxiety & 0.513 & 0.052 \\
Anger-Hostility & 0.355 & \\
Confusion & &
\end{tabular}

${ }^{*} \mathrm{p}<0.05,{ }^{* *} \mathrm{p}<0.001$; The values are correlation coefficient. 
with the factors "feel relaxed" $(r=-0.896, p<0.001)$ and "feel soothed" ( $r=$ $-0.684, p=0.014)$ as indicated by the increase in the VAS scores. Therefore, in this study, we found that the healing effects and autobiographical memories induced from smelling the soil may lead to hyperactivity of parasympathetic nerve functions or suppression of sympathetic nerve functions which may influence the heart rate.

\section{Acknowledgements}

We would like to express our appreciation to the participants for their cooperation in this study. Also, we would like to express our gratitude to the Tsukuba University of Technology for allowing us to use their laboratories.

\section{References}

[1] Sumitomo, K., Maeda, R., Tsuchiya, S., Igari, F., Ibaraki, Y., Hasebe, N. and Kikuchi, K. (2006) Forest Relaxation as an Alternative Medicine of Hypertension Therapy. The Japanese Forest Society, 48, 21-25.

[2] Kondo, T., Takeda, A., Takeda, N., Shimomura, Y., Yatagai, M., Kobayashi, I., Seki, K., Fukumura, K., Murakami, M., Yamaguchi, T. and Tomioka, A. (2007) A Physiological Research on Shinrin-Yoku-Analysis of Its Mind-Healing and Health Keeping Effect in the Kawaba Forest Walking. Paz-Bulletin, 4, 435-442.

[3] Mitchell, R. and Popham, F. (2008) Effect of Exposure to Natural Environment on Health Inequalities: An Observational Population Study. The Lancet, 372, 1655-1660. https://doi.org/10.1016/S0140-6736(08)61689-X

[4] Tamura, K. (2005) Soil Making of Fields and Rice Field to Reproduce the Natural Power of Forest Soil. Food and Agriculture Education, 43, 32-37.

[5] Crowell, P.L. (1999) Prevention and Therapy of Cancer by Dietary Monoterpenes. The Journal of Nutrition, 129, 775s-778s.

[6] Sun, J. (2007) D-Limonene: Safety and Clinical Applications. Alternative Medicine Review, 12, 259-264.

[7] Kusuhara, M., Urakami, K., Masuda, Y., Zangiacomi, V., Ishii, H., Tai, S., Maruyama, K. and Yamaguchi, K. (2012) Fragrant Environment with $\alpha$-Pinene Decreases Tumor Growth in Mice. Biomedical Research, 33, 57-61. https://doi.org/10.2220/biomedres.33.57

[8] Nakamura, M., Sumitomo, K., Akutsu, H., Fukuyama, S., Yamamura, Y., Kukita, S., Satou, K., Osanai, S., Funakoshi, H. and Hasebe, N. (2014) Transfer of Conifer-Derived Aroma Volatiles to Forest Walkers. Aroma Research, 59, 56-61.

[9] Hanyu, K., Tamura, K. and Mori, H. (2014) Changes in Heart Rate Variability and Effects on POMS by Whether or Not Soil Observation Was Performed. Open Journal of Soil Science, 4, 36-41. https://doi.org/10.4236/ojss.2014.41005

[10] Pomeranz, B., Macaulay, R.J., Caudill, M.A., Kutz, I., Adam, D., Gordon, D., Kilborn, K.M., Barger, A.C., Shannon, D.C., Cohen, R.J. and Benson, H. (1985) Assessment of Autonomic Function in Humans by Heart Rate Spectral Analysis. American Journal of Physiology, 248, h151-h153.

[11] Berntson, G.G., Cacioppo, J.T. and Quigley, K.S. (1993) Respiratory Sinus Arrhythmia: Autonomic Origins, Physiological Mechanisms, and Psychophysiological Implications. Psychophysiology, 30, 183-196. https://doi.org/10.1111/j.1469-8986.1993.tb01731.x 
[12] Kasetani, T. (2007) Psychological Relax Effects of Forest Therapy. Research Journal of Food and Agriculture, 30, 20-23.

[13] Arashida, E., Tsukagoshi, S., Noda, K., Kita, T., Ohgama, T., Komiyama, M. and Ikegami, F. (2007) Psychological and Physiological Verification of the Therapeutic Effects of Horticultural Activity Mainly with Herbs (Human Issues \& Methodology in Horticulture). The Horticulture Journal, 6, 491-496.

[14] Willander, J. and Larsson, M. (2006) Smell Your Way Back to Childhood: Autobiographical Odor Memory. Psychonomic Bulletin \& Review, 13, 240-244. https://doi.org/10.3758/BF03193837

[15] Herz, R.S. and Schooler, J.W. (2002) A Naturalistic Study of Autobiographical Memories Evoked by Olfactory and Visual Cues: Testing the Proustian Hypothesis. The American Journal of Psychology, 115, 21-32. https://doi.org/10.2307/1423672

[16] Hayano, J., Yamada, M., Fujinami, T., Yokoyama, K., Watanabe, Y. and Takata, K. (1988) Spectral Component of Heart Rate Variability as an Index of Autonomic Nervous Function. The Biophysical Society of Japan, 28, 198-202.

https://doi.org/10.2142/biophys.28.198

\section{Submit or recommend next manuscript to SCIRP and we will provide best} service for you:

Accepting pre-submission inquiries through Email, Facebook, LinkedIn, Twitter, etc. A wide selection of journals (inclusive of 9 subjects, more than 200 journals)

Providing 24-hour high-quality service

User-friendly online submission system

Fair and swift peer-review system

Efficient typesetting and proofreading procedure

Display of the result of downloads and visits, as well as the number of cited articles

Maximum dissemination of your research work

Submit your manuscript at: http://papersubmission.scirp.org/

Or contact ojss@scirp.org 